and phonon spectra should also be calculated and measured. One might expect orbitons to occur in other orbitally ordered materials, such as high-temperature superconductors. Indeed, the partially empty $d$ orbital shell of $\mathrm{Cu}^{2+}$ in copper oxide superconductors can have orbital excitations. Over a decade ago, these excitations were used by Weber ${ }^{7}$ in a theory of the superconducting coupling between electrons that allows them to flow without resistance. Perhaps he should revive his theory now that the orbiton's existence is more established.
Philip B. Allen and Vasili Perebeinos are in the Department of Physics and Astronomy, State University of New York, Stony Brook, New York 11794-3800, USA.

e-mail:allen@felix.physics.sunysb.edu

1. Saitoh, E. et al. Nature 410, 180-183 (2001).

2. Moussa, F. et al. Phys. Rev. B 54, 15149-15155 (1996).

. Murakami, Y. et al. Phys. Rev. Lett 81, 582-585 (1998).

4. Okamoto, S., Ishihara, S. \& Maekawa, S. Phys. Rev. B 61, 14647-14655 (2000).

5. Hotta T., Malvezzi, A. L. \& Dagotto, E. Phys. Rev. B 62, 9432-9452 (2000).

6. Allen, P. B. \& Perebeinos, V. V. Phys. Rev. Lett. 83, 4828-4831 (1999).

7. Weber, W. Z. Phys. B 70, 323-329 (1988).

Evolutionary biology

\title{
What's in a baboon's behind?
}

\section{R. I. M. Dunbar}

It is often thought that sexual 'ornaments', such as the swellings that adorn ovulating female baboons, are signalling something about fertility but what? Long-term studies of wild baboons provide an answer.

$\mathrm{T}$ he Victorians were so embarrassed by the large swellings that occasionally adorn the bottoms of some primate species - notably baboons and chimpanzees - that many zoos insisted that females in this condition be kept out of public view. The swellings, which occur in about $10 \%$ of all primate species, can be so large and grotesque that females cannot sit comfortably. Less squeamish primatologists of subsequent eras remained puzzled by this all but unique phenomenon. The fact that swellings coincide with ovulation made it obvious that females must be signalling something about their fertility, but exactly what remained elusive. On page 204 of this issue ${ }^{1}$, Domb and Pagel show that females are in fact signalling their own genetic quality.

Sexual swellings are found only among Old World monkeys and apes. Detailed analyses of the distribution of swellings indicate that they have evolved independently in three quite separate lineages. Typically they are associated with the evolution of social groups containing several males and several females, where mating is promiscuous and females have greater choice in mating partners ${ }^{2-5}$. Swellings are seen, for example, in chimpanzees, whose mating system is close to a sexual freefor-all. But - as readers have no doubt noticed - they do not occur in the chimpanzees' closest relatives (our own species), whose mating system is typically, though by no means exclusively, focused on monogamous couples.

Five explanations for the evolution of sexual swellings have been offered ${ }^{4,6}$. First, females want to attract males to join their groups, so as to provide the females and their young with an effective defence against predators. Second, females are in effect try-

ing to provoke males into competing among themselves for opportunities to mate, thereby enabling the females to mate with the 'best' males in the group (a form of indirect female choice). Third, females are encouraging promiscuous mating so as to confuse paternity. This would mean that the risk of killing their own offspring deters males from infanticide - a problem that is particularly serious for primates because they have long intervals between births ${ }^{7}$. Fourth, given that the timing of ovulation is itself unpredictable, females want to persuade individual males to stay with them. This would assure the males of paternity, and provide the females with a bodyguard so as to reduce the levels of harassment that they would otherwise suffer in multimale groups (this is the 'hired-gun' hypothesis). And fifth, swelling size is an indicator of a female's genetic quality, enabling her to attract the best males to mate with her and so maximize the genetic quality of her offspring ${ }^{8}$.

One of the problems that evolutionary biologists have encountered in trying to test these hypotheses is that they often make similar predictions. As a result, comparative data drawn from across the primate species are often compatible with several hypotheses; indeed, there is evidence to support all five hypotheses ${ }^{4}$. In such cases, to choose between competing theories we need to explore the mechanisms involved in more detail, rather than just look at the superficial phenomenon.

Domb and Pagel $^{1}$ provide the first uncontroversial mechanistic evidence that the size of sexual swellings is correlated with a male's willingness to compete for individual ovulating females, and with indices of a female's own fitness. The authors were able to reach this conclusion only because they used long- term demographic data from the baboon population that (together with Jane Goodall's more famous chimpanzees) inhabits the Gombe National Park, Tanzania. Both the chimp and the baboon populations have been under continuous study for more than 30 years.

Domb and Pagel show that the females with the largest swellings had attained sexual maturity earlier (and so had longer reproductive lifespans) than those with smaller swellings. The females with larger swellings also produced more offspring, as well as more surviving offspring, over their lifetime. Males competed more heavily, and incurred more injuries from fighting, for females with larger swellings. As males are willing to do this, it follows that they must be using swelling size as an index of a female's heritable reproductive quality. These findings thus explain why there are such consistent differences between females in the size and quality of their swellings. But it may not explain why sexual swellings evolved in the first place - it is possible that females have exploited for this new purpose a signal that first evolved for one of the other reasons.

Evolutionary biologists have been much exercised of late as to whether such signals of quality have to be honest, by which they mean costly to produce. Although there is some evidence to suggest that this need not always be so, most theoretical models of signal evolution agree that when cues are cheap to produce they are too susceptible to cheating, and so are evolutionarily unstable. Herein, perhaps, lies the weak link in Domb and Pagel's argument — they are able to provide only circumstantial evidence that swellings are costly for females to produce. Their evidence is that female body weight increases by 14 to $25 \%$ when swellings are at their maximum size. It is unlikely that the swellings are in themselves energetically expensive, because they are produced simply by the selective retention of extracellular water. But it is possible that they make females less fleet - and thus at greater risk of being caught by a predator - and that carrying the added weight increases the energetic costs of travel. If either of these could be demonstrated, the case would be satisfyingly closed.

R. I. M. Dunbar is in the Population and

Evolutionary Biology Division, School of Biological Sciences, Nicholson Building, University of

Liverpool, Liverpool L69 3GS, UK.

e-mail:rimd@liv.ac.uk

\section{Domb, L. G. \& Pagel, M. Nature 410, 204-206 (2001).}

2. Hrdy, S. B. \& Nicholson, N. in Primate Societies (eds Smuts,

B. B., Cheney, D. L., Seyfarth, R. M., Wrangham, R. W. \& Struhsaker, T. T.) 370-384 (Chicago Univ. Press, 1987).

3. Sillén-Tullberg, B. \& Møller, A. P. Am. Nat. 141, 1-25 (1993).

4. Nunn, C. L. Anim. Behav. 58, 229-246 (1999).

5. Dixson, A. F. Primate Sexuality (Oxford Univ. Press, 1998).

6. Manson, J. H. Curr. Anthropol. 38, 353-374 (1997).

7. van Schaik, C. P. \& Kappeler, P. M. Proc. R. Soc. Lond. B 264, 1687-1694 (1997).

8. Pagel, M. Anim. Behav. 47, 1333-1341 (1994). 